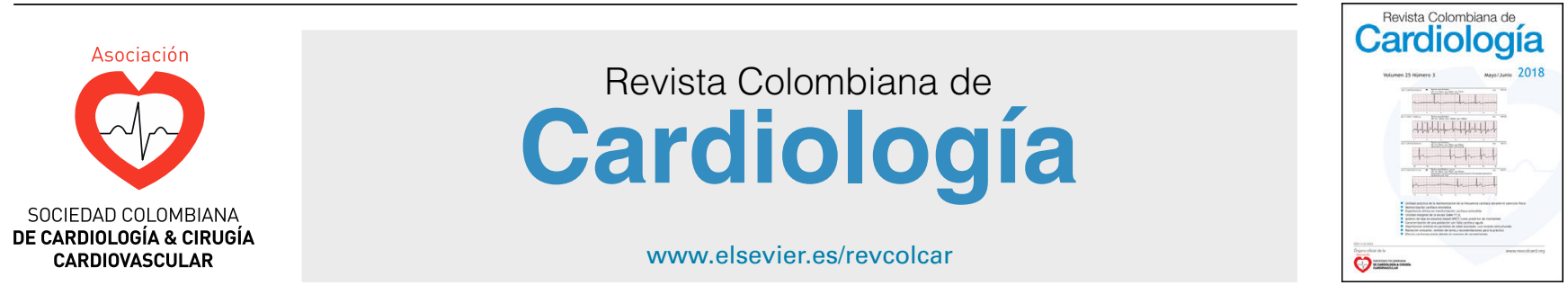

ADULT CARDIOLOGY - ORIGINAL ARTICLE

\title{
Cost-effectiveness of new oral anticoagulants and warfarin in atrial fibrillation from adverse events perspective
}

\author{
José A. Mendoza ${ }^{\mathrm{a}, *}$, Federico A. Silva ${ }^{\mathrm{b}}$, Lady M. Rangel ${ }^{\mathrm{b}}$ \\ a Grupo de Ciencias Neurovasculares, Instituto Neurológico, Hospital Internacional, Fundación Cardiovascular de Colombia, \\ Floridablanca, Colombia \\ b Universidad Industrial de Santander. Bucaramanga, Colombia
}

Received 17 March 2017; accepted 9 October 2018

Available online 9 April 2019

\author{
KEYWORDS \\ Economic evaluation; \\ Stroke; \\ Warfarin; \\ Dabigatran; \\ Rivaroxaban; \\ Anticoagulants
}

\begin{abstract}
Objective: new oral anticoagulants (apixaban, dabigatran and rivaroxaban) are the newest advance for stroke's risk reduction in atrial fibrillation. These are as effective as warfarin in preventing stroke/systemic embolism, but exists heterogenic outcomes as gastrointestinal hemorrhage, mortality reduction, minor and major haemorrhage (adverse events). Despite of this, there is a lack of cost-effectiveness models focused on adverse events.

Methods: a cost-effectiveness analysis with a third payer perspective, interventions included were apixaban, dabigatran, warfarin and rivaroxaban. Discount rate of $3 \%$, and 10 years of temporal horizon. The Markov model is an international, validated, and modified to assess better adverse events. Major assumptions, patients with mild and moderate stroke returns to oral anticoagulation, patients with moderate and severe hemorrhage do not returns to oral anticoagulation. Probabilities and QALYs, taken from a cost-effectiveness analysis published. Costs, information from a cohort of stroke patients. Software, TreeAge pro ${ }^{T M}$ and Excel ${ }^{T M}$. Results: overall results, 1.48 QALYs, \$17 916 USD for apixaban, 1.49 QALYs, \$18 122 USD for dabigatran, 1.32 QALYs, \$21966 USD for warfarin and 1.24 QALYs, \$24 547 USD for rivaroxaban. The ICER for apixaban compared to dabigatran was $\$ 12988$ USD. Negative ICER for warfarin and rivaroxaban, shows that are dominated alternatives (less benefits and more costs). Apixaban is cost-effective at $70 \%$ and dabigatran at $30 \%$ of iterations in the probabilistic sensitivity analysis.
\end{abstract}

\footnotetext{
Abbreviations: AF, atrial fibrillation; $\mathrm{ICH}$, intracranial hemorrhage; $\mathrm{GIH}$, gastrointestinal hemorrhage; CEA, cost-effectiveness analysis; ICER, incremental cost-effectiveness analysis.

Abreviaturas: AF, fibrilación auricular; $\mathrm{ICH}$, hemorragia intracraneal; $\mathrm{GIH}$, hemorragia gastrointestinal; CEA, Análisis de costoefectividad; ICER, radio costo-efectividad incremental.

* Corresponding author.

E-mail address: jmendoza45@msn.com (J.A. Mendoza). 
Conclusions: apixaban and dabigatran are cost-effective alternatives, apixaban is the most cost-effective alternative from adverse events perspective. Warfarin shows better results than rivaroxaban to prevent stroke in atrial fibrillation from adverse events perspective.

(c) 2019 Sociedad Colombiana de Cardiología y Cirugía Cardiovascular. Published by Elsevier España, S.L.U. This is an open access article under the CC BY-NC-ND license (http:// creativecommons.org/licenses/by-nc-nd/4.0/).

\section{PALABRAS CLAVE}

Evaluación económica; Ictus; Warfarina; Dabigatrán; Rivaroxabán; Anticoagulantes

\section{Introduction}

New oral anticoagulants (apixaban, dabigatran and rivaroxaban) are the latest advance in atrial fibrillation (AF). Some of them are effective as warfarin, reducing stroke/systemic embolism (RR 0.78 95\% Cl 0.67-0.92) and intracranial hemorrhage $(\mathrm{ICH}) \quad(\mathrm{RR} \quad 0.49 \quad 95 \% \quad \mathrm{Cl} \quad 0.36-0.66)^{1}$. But exists heterogeneous outcomes as in gastrointestinal hemorrhage $(\mathrm{GIH})^{2}$, mortality reduction, minor and major hemorrhage $^{3-5}$. Moreover, exist differences in stroke and $\mathrm{ICH}$ rates between them and increase of $\mathrm{GIH}$ compared with warfarin. These heterogeneous outcomes (especially in adverse events), higher drug cost yield us to propose -an improvement on calculation of adverse events in economic evaluations of new oral anticoagulants.

\section{Análisis de costo-efectividad de los nuevos anticoagulantes orales y la warfarina en fibrilación auricular desde la perspectiva de los eventos adversos}

\begin{abstract}
Resumen
Introducción: los nuevos anticoagulantes orales (apixabán, dabigatrán y rivaroxabán) son el avance más reciente para la reducción del riesgo de accidente cerebrovascular en la fibrigastrointestinal, reducción de la mortalidad y hemorragia menor y mayor (eventos adversos). Pese a ello, se carece de modelos de costo-efectividad enfocados en eventos adversos. Materiales y métodos: se hizo un análisis de costo-efectividad con una perspectiva de terrivaroxabán. La tasa de descuento fue del 3\% y 10 años de horizonte temporal. El modelo de Markov es internacional, validado y modificado para evaluar mejor eventos adversos. Las principales suposiciones, los pacientes con accidente cerebrovascular leve y moderado vuelven a la a agulación oral. Probabilidades y AVAC, tomados de un análisis de costo-efectividad publicado. Los costos, información de una cohorte de pacientes con accidente cerebrovascular. Software,

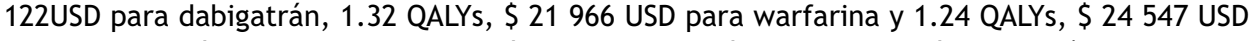
para rivaroxabán. El ICER para apixabán en comparación con dabigatrán fue de \$12 988 USD. El ICER negativo para warfarina y rivaroxabán muestra que son alternativas dominadas (menos beneficios y más costos). Apixabán es rentable en $70 \%$ y dabigatrán en $30 \%$ de las iteraciones Conclusión: apixabán y dabigatrán son costo-efectivos; apixabán es la alternativa más costoefectiva desde la perspectiva de los eventos adversos. Warfarina mostró mejores resultados que rivaroxabán para prevenir accidentes cerebrovasculares en fibrilación auricular desde la perspectiva de los eventos adversos.

(C) 2019 Sociedad Colombiana de Cardiología y Cirugía Cardiovascular. Publicado por Elsevier España, S.L.U. Este es un artículo Open Access bajo la licencia CC BY-NC-ND (http:// creativecommons.org/licenses/by-nc-nd/4.0/).
\end{abstract}


apixaban, \$28 796 USD for dabigatran and \$26 340 USD for rivaroxaban ${ }^{10}$.

Most of published CEA differs on the Markov model's structure, but are similar in lacking of more specific adverse events (AE) calculations; a systematic review found that the current modelling assumptions may restrict the understanding of the true impact of AE in CEA of antineoplastic drugs $^{11}$, however, for oral anticoagulation this impact is unknown, despite the hemorrhage events are almost two times more than ischemic stroke in pivotal clinical trials ${ }^{3-5}$. The assessment of hemorrhage localization are important due to cost of treatment, for example, the treatment cost of mild upper $\mathrm{GIH}$, severe lower $\mathrm{GIH}$; mild intraparenchymal ICH and severe subdural ICH differs. We propose a CEA in oral anticoagulation in atrial fibrillation in Colombia with the improve on hemorrhage events assessment by localization of intracranial hemorrhage and gastrointestinal hemorrhage, using an international validated Markov model and costs data from a cardiovascular hospital in Colombia, with the aim of identify the most efficient alternative in oral anticoagulation.

\section{Methods}

Several Markov models in anticoagulation are described in the literature, for the study we used the Harrington's model as a base from which we modified ICH and GIH to classify events by localization. Four treatment strategies and their associated outcomes were assessed: warfarin (INR 23), dabigatran (150 mg twice daily), apixaban (5 mg twice daily), and rivaroxaban ( $20 \mathrm{mg}$ once daily). The hypothetical cohort of patients with $\mathrm{AF}$, and same characteristics as included in pivotal clinical trials. For this model rate of adherence and drug compliance were assumed the same across of the treatments. The Markov model was designed to move between health states of 1 month cycles for 10 years or until death. Cost-effective therapies were selected using a willingness-to-pay (WTP) threshold of \$9 000 USD per quality-adjusted life-year (QALY) gained (approximately 3 times per capita gross domestic product) and 3\% discount rate. Model's calculations and sensitivity analysis were made using TreeAge pro ${ }^{\circledR}$.

\section{Model structure}

The model inputs of events were taken from literature. The aim was to simulate a cohort of patients with AF that has the similar adherence rate between drugs. It was used major probabilities as risk of stroke, $\mathrm{ICH}, \mathrm{GIH}$ and other hemorrhage; other bleeding included retroperitoneal hemorrhage, epistaxis, and urinary tract hemorrhage ${ }^{12}$. Events risks calculations of new oral anticoagulants (NOAC) were based on information of pivotal clinical trials (ARISTOTLE, RE-LY, and ROCKET-AF); warfarin probabilities were calculated from pooled clinical trials results. Distribution of stroke rate severity was the same for NOAC and warfarin; it was extracted from Leigh's et al study ${ }^{13}$. Distribution of intracerebral, subdural (intracranial), upper, and lower (gastrointestinal) hemorrhage was taken from economic model of Leigh et al.
For the assessment of a more realistic model in oral anticoagulation, it was used information from a cohort of stroke in a cardiovascular hospital, which was useful to know the physician's believe of hemorrhage and its attitude to restart oral anticoagulation after a major hemorrhage; from this, our model excluded patients with moderate or severe $\mathrm{GIH}$, all the $\mathrm{ICH}$, and moderate stroke and severe stroke, this last one is not consider an adverse event for oral anticoagulation but there are a risk of hemorrhagic transformation of stroke.

\section{Utilities}

There is a lack of calculation for QALY's utilities in Colombia. Exists literature descriptions of the baseline utility of a patient with $\mathrm{AF}$ in oral anticoagulation treatment, disutilities for stroke (mild, moderate, and severe), intracranial haemorrhage (mild and severe), gastrointestinal haemorrhage (mild, moderate, and severe), other hemorrhage was used from US information.

\section{Costs}

Events costs were estimated from information of a cohort of patients with stroke in the Fundación Cardiovascular de Colombia. From resource individual information recollected from November 2015 to January 2018 of patients with stroke, we calculated event's costs considered:

1. Time hospitalization (general hospitalization, intensive care unit)

2. Medical supplies

3. Drug costs

4. Laboratory test

5. Cost of medical consultation

6. Cost of procedures (craniotomy, endoscopy, and colonoscopy).

7. Medical fees.

Drugs' costs were taken from the SISMED database, which is a ministry's of health database ${ }^{14}$. Drug's costs are reported in monthly Colombian pesos, for the use in the model the cost were convert in dollars using the representative rate for May of 2015. Cost of anticoagulation of warfarin and new oral anticoagulants were calculated from expert opinion of monthly controls of international normalized ratio (INR), and follow by specialist or general practitioner.

\section{Sensitivity analyses}

A several sensitivity analyses were conducted. As a first step a univariate analysis was useful for identify the most influence model's parameters and their impact on the final decision. Finally, a probabilistic sensitivity analysis was done, we used dirichlet distributions for probabilities and utilities, whereas normal distribution was used for cost (Table 1). 
Table 1 Model parameters.

\begin{tabular}{|c|c|c|c|c|c|c|c|}
\hline Parameters & Base & Ref & Distri & Parameters & Base & Ref & Distri \\
\hline Stroke, Warfarin & & & & pGIH_upper_mild_NOAC & 0.48 & (13) & \\
\hline pStroke_war & 0.0110 & $(12)$ & dirichlet & pGIH_upper_severe_NOAC & 0.48 & (13) & \\
\hline pStroke_mild_warf & 0.075 & (13) & & pGIH_upper_death_NOAC & 0.05 & (13) & \\
\hline pStroke_mod_warf & 0.41 & (13) & & pGIH_lower_mild_NOAC & 0.44 & (13) & \\
\hline pStroke_sev_warf & 0.465 & (13) & & Other bleeding warfarin & & & \\
\hline Stroke, NOAC & & & & pOtherbleeding_warf & 0.0015 & (13) & dirichlet \\
\hline pstroke_apixaban & 0.0088 & $(12)$ & dirichlet & pOtherbleeding_death_warf & 0.003 & (13) & dirichlet \\
\hline pStroke_dabigatran & 0.0091 & (12) & dirichlet & Other bleeding, NOAC & & & \\
\hline pStroke_rivaroxaban & 0.0110 & (12) & dirichlet & pOther_bleeding_NOAC & 0.0015 & (13) & dirichlet \\
\hline pStroke_moderate_NOAC & 0.415 & (13) & & pOther_bleeding_death_NOAC & 0.003 & (13) & dirichlet \\
\hline pStroke_severe_NOAC & 0.392 & (13) & & pGIH_lower_severe_NOAC & 0.44 & (13) & \\
\hline pStroke_death_NOAC & 0.102 & (13) & & pGIH_lower_death_NOAC & 0.12 & (13) & \\
\hline $\mathrm{ICH}$, warfarin & & & & COSTS & & & \\
\hline plCH_subdural_warf & 0.54 & (13) & & warfarin & $\$ 12.5$ & (14) & normal \\
\hline pICH_intracerebral_warf & 0.46 & (13) & & Apixaban & $\$ 67.5$ & (14) & normal \\
\hline pICH_subdural_mild_warf & 0.4 & (13) & & Dabigatrán & $\$ 53.33$ & (14) & normal \\
\hline pICH_subdural_severe_warf & 0.4 & (13) & & Rivaroxaban & $\$ 45.16$ & (14) & normal \\
\hline pICH_intracerebral_mild_warf & 0.1 & (13) & & Stable atrial fibrillation & & & \\
\hline pICH_intracerebral_severe_warf & 0.35 & (13) & & cAFstable_warf & $\$ 20.91^{*}$ & & normal \\
\hline pICH_intracerebral_death_warf & 0.55 & (13) & & cStable_NOAC & $\$ 8^{*}$ & & normal \\
\hline ICH, NOAC & & & & Event costs, Stroke & & & \\
\hline plCH_apixaban & 0.0029 & $(12)$ & dirichlet & cStroke_mild & $\$ 1.0009$ & & normal \\
\hline pICH_dabigatran & 0.0031 & (12) & dirichlet & cStroke_moderate & $\$ 2.8699$ & & normal \\
\hline pICH_rivaroxaban & 0.0039 & $(12)$ & dirichlet & cStroke_severe & $\$ 3.4769$ & & normal \\
\hline pHIC_subdural_NOAC & 0.54 & (13) & & HIC, Cost & & & \\
\hline pHIC_intracerebral_NOAC & 0.46 & (13) & & clCH_mild & $\$ 1.0009$ & & normal \\
\hline pHIC_subdural_mild_NOAC & 0.4 & (13) & & ClCH_severe & $\$ 6.6679$ & & normal \\
\hline pHIC_subdural_severe_NOAC & 0.4 & (13) & & GIH, Cost & & & \\
\hline pHIC_subdural_death_NOAC & 0.2 & (13) & & cGIH_mild & $\$ 1.0009$ & & normal \\
\hline pHIC_intracerebral_mild_NOAC & 0.1 & (13) & & cGIH_moderate & $\$ 1.7799$ & & normal \\
\hline pHIC_intracerebral_death_NOAC & 0.55 & (13) & & cGIH_severe & $\$ 3.8759$ & & normal \\
\hline GIH, warfarin & & & & Other costs & & & \\
\hline pGI_warf & 0.0089 & $(12)$ & dirichlet & cOtherbleeding & $\$ 509$ & & normal \\
\hline pGI_upper_warf & 0.76 & (13) & dirichlet & cDeath & $\$ 3.0009$ & & normal \\
\hline pGI_lower_warf & 0.24 & (13) & & EFFICACY & & & \\
\hline pGI_upper_mild_warf & 0.48 & (13) & & eff_AF_estable & 0.80 & $(12)$ & dirichlet \\
\hline pGI_upper_severe_warf & 0.48 & (13) & & eff_QALY_stroke_mild & 0.51 & $(12)$ & dirichlet \\
\hline pGI_upper_death_warf & 0.04 & (13) & & eff_QALY_stroke_moderate & 0.43 & $(12)$ & dirichlet \\
\hline pGI_lower_mild_warf & 0.44 & (13) & & eff_QALY_stroke_severe & 0.35 & (12) & dirichlet \\
\hline pGI_lower_severe_warf & 0.44 & (13) & & eff_QALY_HIC_mild & 0.51 & (12) & dirichlet \\
\hline pGI_lower_death_warf & 0.12 & (13) & & eff_QALY_HIC_severe & 0.35 & (12) & dirichlet \\
\hline GIH, NOAC & & & & eff_QALY_GIH_mild & 0.75 & (12) & dirichlet \\
\hline pGIH_dabigatran & 0.0154 & $(12)$ & dirichlet & eff_QALY_GIH_severe & 0.50 & (12) & dirichlet \\
\hline pGIH_rivaroxaban & 0.0156 & (12) & dirichlet & eff_QALY_menorHemorhage & 0.80 & (12) & dirichlet \\
\hline pGIH_apixaban & 0.0058 & (12) & dirichlet & & & & \\
\hline pGIH_upper_NOAC & 0.76 & (13) & & & & & \\
\hline pGIH_lower_NOAC & 0.24 & (13) & & & & & \\
\hline
\end{tabular}

Distri: distribution; Ref: references; NOAC: New oral anticoagulants; *: expert opinion; $\uparrow$ : costs from stroke cohort study.

\section{Results}

\section{Base case analysis}

The results were: a quality adjusted life expectancy of 1.48 years and total healthcare cost of \$17 916 USD for apixaban, 1.49 QALY and cost of \$18 122 USD for dabigatran, 1.32 QALY and cost of \$21 966 USD for warfarin, and 1.24 QALY total cost of \$24 547 USD for rivaroxaban (Table 2). The incremental cost and QALY for dabigatran compared to apixaban were $\$ 206$ and 0.01, the incremental cost and QALY for warfarin compared to dabigatran were \$3844 USD and -0.17 , and incremental cost and QALY of rivaroxaban compared with warfarin were \$2 581 USD and -0.08. In the ranking (the less costly from the most costly) warfarin and Rivaroxaban were dominated (more expensive and less QALYs). 
Table 2 Study's results.

\begin{tabular}{|c|c|c|c|c|c|c|c|c|}
\hline & \multirow[b]{2}{*}{ Overall Cost } & \multicolumn{3}{|c|}{ Base case } & \multicolumn{4}{|c|}{ Probabilistic sensitivity analysis } \\
\hline & & QALY & C/E & ICER & Overall Cost & QALY & $\mathrm{C} / \mathrm{E}$ & ICER \\
\hline Apixaban & $\$ 17916$ & 1.48 & $\$ 12116$ & & $\$ 17734$ & 1.56 & $\$ 11357$ & \\
\hline Dabigatrán & $\$ 18122$ & 1.49 & $\$ 12125$ & $\$ 12998$ & $\$ 18197$ & 1.57 & $\$ 11564$ & $\$ 38453$ \\
\hline Warfarin & $\$ 21966$ & 1.32 & $\$ 16690$ & $\$-21544$ & $\$ 20477$ & 1.40 & $\$ 14583$ & $\$-13466$ \\
\hline Rivaroxaban & $\$ 24547$ & 1.24 & $\$ 19750$ & $\$-25536$ & $\$ 24317$ & 1.35 & $\$ 17996$ & $\$-12156$ \\
\hline
\end{tabular}

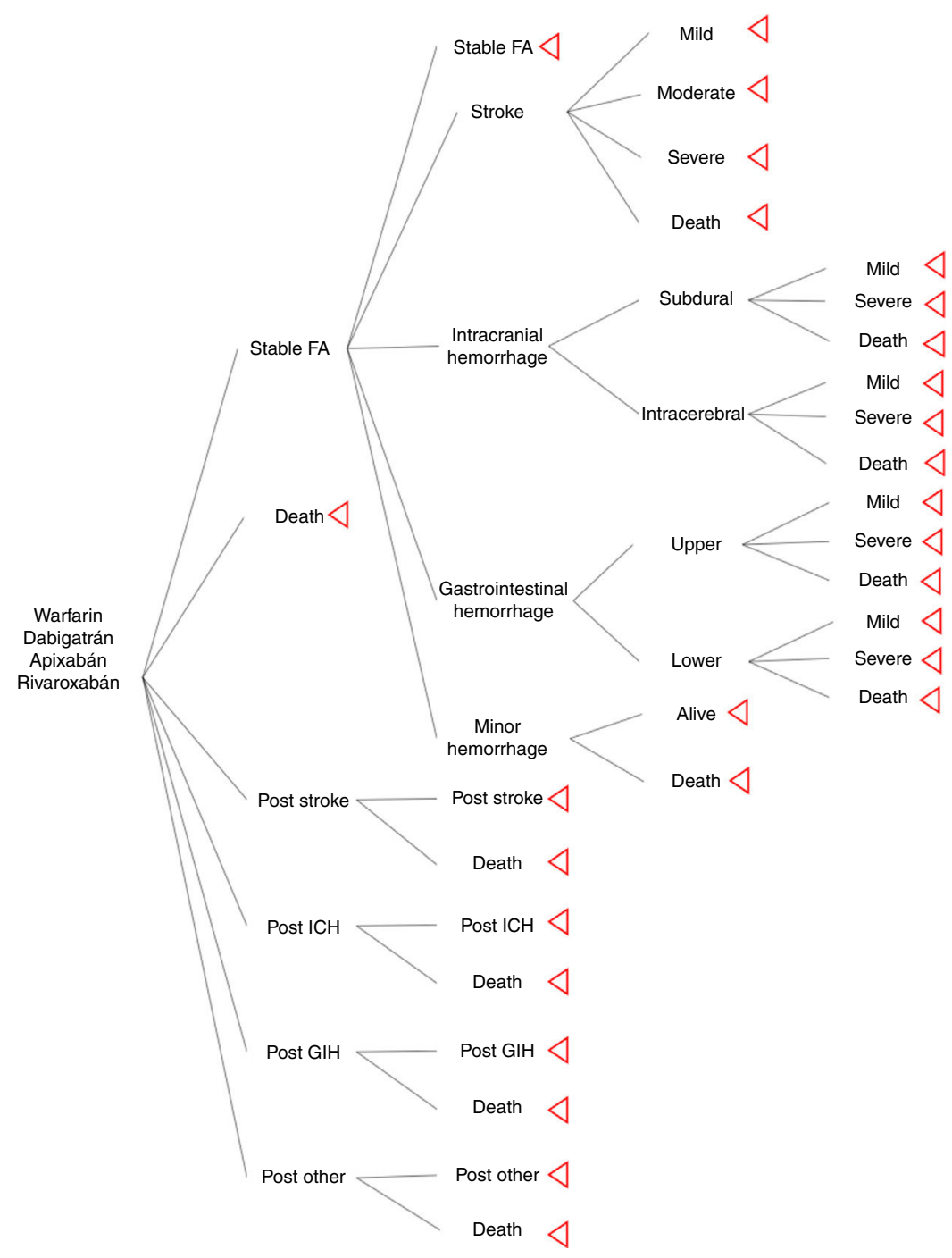

Figure 1 Model Inputs.

The ICER of apixaban compared to dabigatran (undominated alternatives) was \$12 998 USD, and negatives ICER's for warfarin and rivaroxaban (dominated alternatives).

\section{Deterministic sensitivity analysis}

The tornado analysis (fig. 2) shows the most sensible variables of this model; probability of HIC and GIH (pHIC and pGIH) for apixaban and dabigatran were the most influential variables (fig. 1, appendix), stroke's probability for apixaban and dabigatran (pStroke) (fig. 2 appendix) also influenced in model. Apixaban and dabigatran's costs were the criteria that influenced the ICER in positive and negative way. Rest of variables were less influential.

\section{Probabilistic sensitivity analysis}

A series of analysis were made (Table 2), mean cost and QALYs were calculated based on probabilistic functions for the model parameters. Results are presented in Table 2, the 


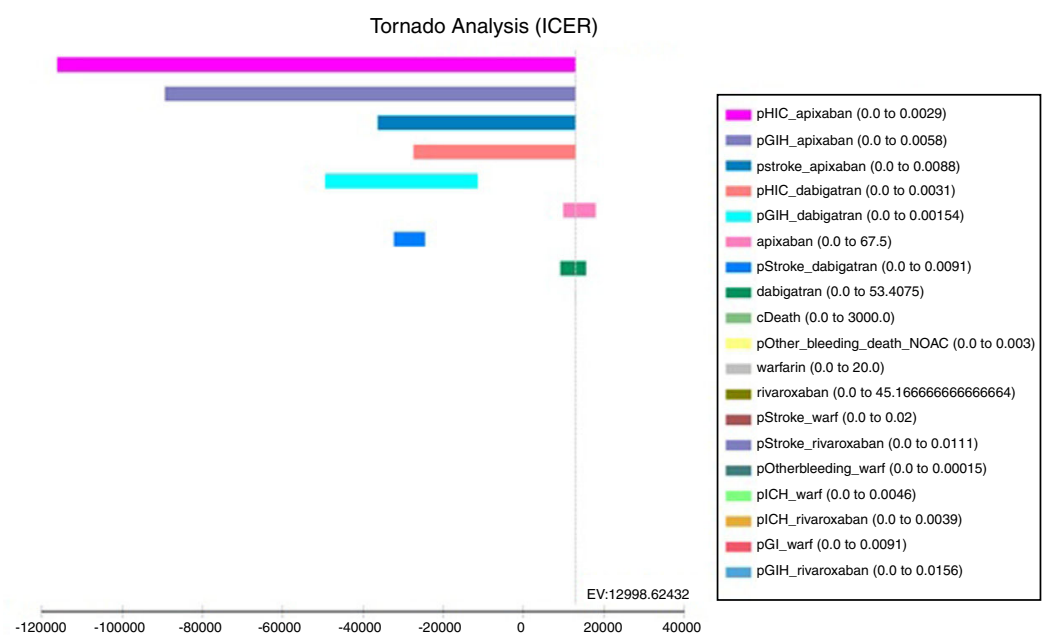

Figure 2 Analysis of ICER variations by parameter.

CE Acceptability Curve

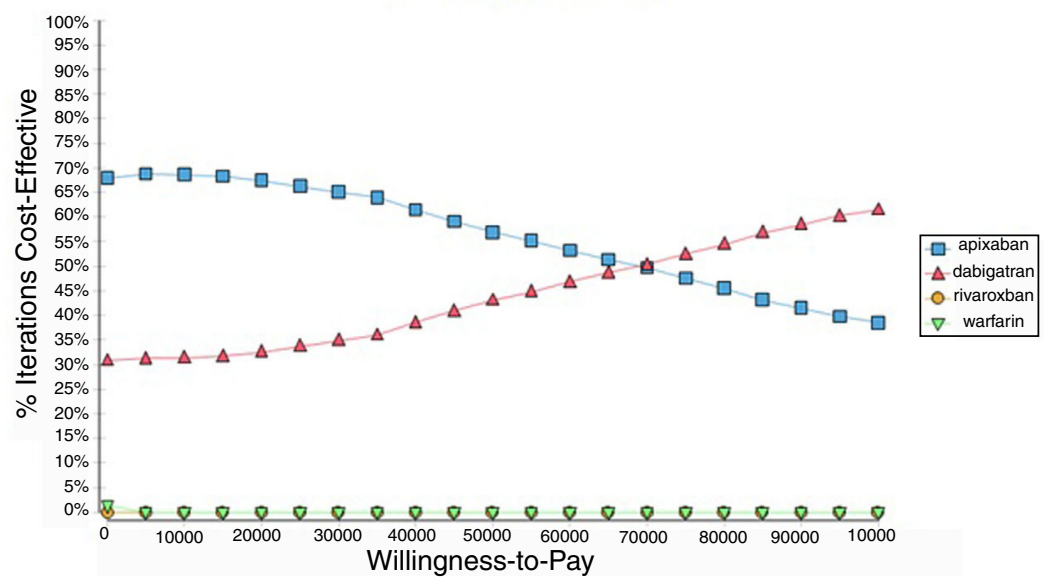

Figure 3 Analysis of cost-effectiveness probabilities.

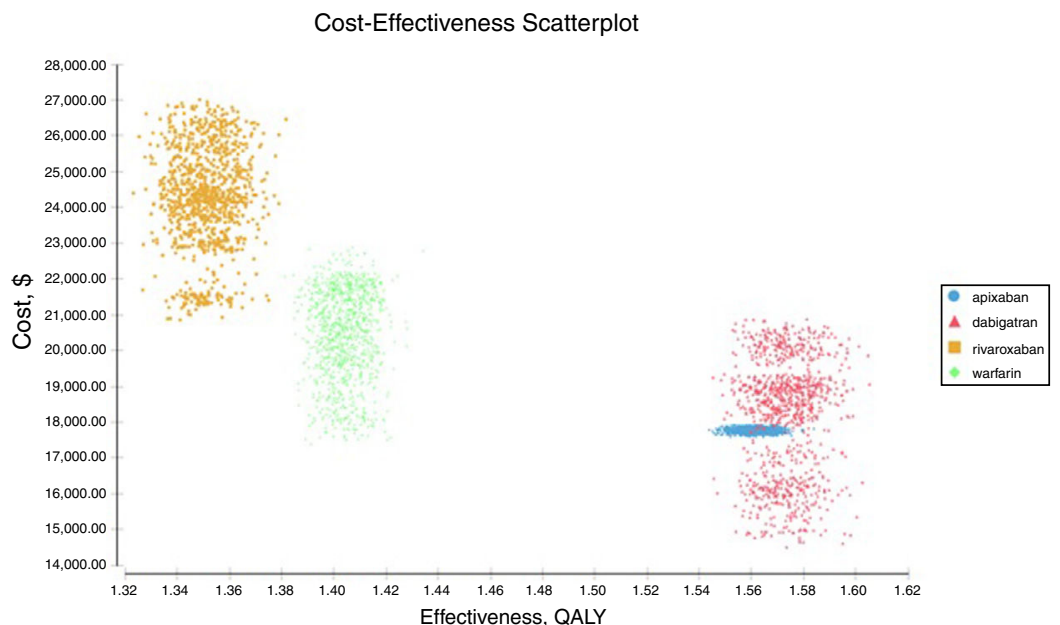

Figure 4 Monte Carlo Analysis, cost and QALY by iterations. 
analysis was analysed under the WTP threshold of $\$ 9000$ USD. The median cost for apixaban was $\$ 17734$ USD with gained QALY of 1.56, Dabigatran median cost was \$18 197 USD with gained QALY of 1.57, warfarin median cost was \$20 477 USD with gained QALY 1.40, and rivaroxaban median cost of \$24 317 USD gained QALY of 1.35. The ICER's for undominated alternatives was $\$ 38.453$. At willingness to pay $\$ 9000$ USD, apixaban is cost-effective at $70 \%$ of iterations, dabigatran at $30 \%$ of iterations, warfarin and rivaroxaban were not (fig. 3). The cost-effectiveness scatterplot shows the point distribution of each option, apixaban's point distribution is close between them, and it confirms the result's robustness (fig. 4).

\section{Discussion}

We found that apixaban is the most cost-effective alternative for stroke prevention in atrial fibrillation from adverse event perspective, following by dabigatran 150, warfarin and finally rivaroxaban. This results from a less cost for apixaban and a minor difference of efficacy compared with dabigatran, and negative ICER's for warfarin and rivaroxaban indicates costlier and less efficacy alternatives. Apixaban accounted less overall cost due to smaller number of adverse events than dabigatran, warfarin and rivaroxaban, despite of greater drug's cost. The tornado type sensitivity analysis confirms that the most important model's parameters were those related to adverse events rates, this confirms the necessity of improve hemorrhage outcomes in anticoagulation models.

From this analysis warfarin was most cost-effective than rivaroxaban, driven by less overall cost (events, drug and controls costs) and best QALY's performance, the explanation is due to less gastrointestinal hemorrhage events in warfarin despite of more $\mathrm{ICH}$; event rates has influence on both (cost and QALY). Clinical trials had shown an unexpected increase in gastrointestinal hemorrhage, especially among patients aged 75 years or over, a meta-analysis of 71.674 patients highlighted a $25 \%$ increase in gastrointestinal hemorrhage compared with warfarin ${ }^{15}$. This caused that warfarin had a best ICER than rivaroxaban (warfarin is dominant for rivaroxaban).

The ICERs can be used to set health priorities in three ways, (i) to minimize the expenditure to achieve a health effect target, (ii) to maximize the health benefits within budget and (iii) to consider cost-effective with an explicit threshold $^{16}$. In Colombia, there is a lack of an explicit ICER to set efficiency treatments, due to the policy is focused on treatment access rather than principle of resources' maximization, but despite of it, WHO's recommendations about thresholds (less 1 GDP is highly C-E and 1-3 GDP is C-E) for middle income countries are considered ${ }^{16}$. From a new law called "ley estatutaria de salud"' that ordered to ministry of health the adoption of a technical-scientific procedure to establish which services could be no afforded, the CEA could be used as a criterion by stakeholders. Is unknown which ICER would be used in the case to choose it, considering that opportunity cost is measure better with other threshold setting techniques as those that take into account the money invested ${ }^{17}$. Our ICER results are robust, uncertainty was measure, which allows the decision-making process - more transparent.

Study's strengths are: use of international validated anticoagulation model, the degree of complication was useful to ensure most of assumptions identified in clinical practice and hemorrhage localization, allowed the incorporation of adverse events by localization; we consider that it is a new model in oral anticoagulation, which incorporates more impact of adverse events. Model is robust, uncertainty for base case and other assumptions were measured, major changes in parameters must to be done to alter study's results. Other strength is the use of cost's information from a Cardiovascular Hospital and the bottom-up resources consumption calculation; this kind of resource utilization offer an opportunity for more detailed data collection ${ }^{18}$. Study's limitations are: use of international QALY's measurement (US), because of lack of Colombian's coefficients calculations for quantitative QALY assessment. We consider that efforts to measure coefficients in our population could be economic evaluations and patient's satisfaction studies more reliable than now, as well as national databases for costs that allow transparent decisions as those that law -indirectly claims.

Decision making process is quite complicated (by stakeholders' perspectives and interests), but decisions on which stakeholders opinions are considered, tend to increase the acceptance ${ }^{19-21}$. From this context, Health Technology Assessments (HTA) helps to provide input to decision making in policy and practice, its orientation is a decision making in a multidisciplinary, comprehensive nature and several perspectives; the main goal of such studies is to improve "value for money" in health care ${ }^{22}$. Multicriteria decision analysis (MCDA) is a tool to assist decision making process, which is used by national agencies to perform HTA as the Scottish Medicines Consortium (SMC). They stated criteria of clinical effectiveness and cost-effectiveness but allows other factors to play role ${ }^{23}$, ICER is important but not -the only factor. New oral anticoagulants are used in clinical practice at this moment in Colombia, this from physician's consideration, but it is no widely used due to administrative restrictions that are changing from new administrative steps. New oral anticoagulants are afforded, but restrictions to contain the expenditure could be established, in this context new oral anticoagulants could be revaluated from other criteria than economic considerations; and a roadmap with stakeholder's participation must to be used.

Roads maps establish steps and the rules to be follow, it is crucial to reach transparent decision and moreover to improve the acceptance. The inclusion of new laws in Colombia lead us to speculate what would be the model to be adopted, but we consider that CEA remain plays a role in the decision process in Colombia; nevertheless, not as has been used until now to reject a technology as the only one criterion. Model parameters from real world data from Colombian' population have to be assess as those that allows QALY measuring and national costs. Major advances had done in Colombian' health system to ensure drug's access for continue giving the best technology as many as possible patients, more advances are necessary to do as defining of Colombian's road maps to decision making process. In this context, exists uncertainty about the play's role of new oral anticoagulants in clinical practice in our country. 


\section{Conclusions}

Most of new oral anticoagulants are cost-effective for stroke prevention in oral anticoagulation in Colombia from adverse events perspectives, apixaban is the most cost-effective and rivaroxaban the last, none one is highly cost-effective if a 9 000 USD threshold is used, but are cost-effective. However warfarin remains be the status quo by proven efficacy and the known risk's profile. From changes in Colombian's health system is unknown the play's role of new oral anticoagulants in clinical practice.

\section{Conflict of interest}

None.

\section{Acknowledgments}

Net Cardiecol, COLCIENCIAS code: 5020-53-731809 bia. Presentation at ISPOR-CO congress 2016, Bogota, Colom-

\section{References}

1. Miller CS, Grandi SM, Shimony A, Filion KB, Eisenberg MJ. Meta-analysis of efficacy and safety of new oral anticoagulants (dabigatran, rivaroxaban, apixaban) versus warfarin in patients with atrial fibrillation. Am J Cardiol. 2012;110:453-60.

2. Holster IL, Valkhoff VE, Kuipers EJ, Tjwa ET. New oral anticoagulants increase risk for gastrointestinal bleeding: a systematic review and meta-analysis. Gastroenterology. 2013;145:105-12.

3. Connolly SJ, Ezekowitz MD, Yusuf S, Eikelboom J, Oldgren J, Parekh A, et al. Dabigatran versus warfarin in patients with atrial fibrillation. N Engl J Med. 2009:1139-51.

4. Granger CB, Hanna M, Wallentin L, et al. Apixaban versus warfarin in atrial fibrillation. N Eng J Med. 2012:366:88-90.

5. Patel MR, Mahaffey KW, Garg J, Pan G, Singer DE, Hacke W, et al. Rivaroxaban versus warfarin in nonvalvular atrial fibrillation. $\mathrm{N}$ Eng J Med. 2011;365:883-91.

6. Drummond MF, Sculpher MJ, Claxton K, Stoddart GL, Torrance $\mathrm{GW}$, et al. Methods for the economic evaluation of health care programmes. Oxford: Oxford University Press; 2015.

7. Tengs TO. Dying too soon: how cost-effectiveness analysis can save lives. National Center for Policy Analysis;. 1997.

8. Ferreira J, Mirco A. Systematic review of cost-effectiveness analyses of novel oral anticoagulants for stroke prevention in atrial fibrillation. Rev Port de Cardiol (English Edition). 2015;34:179-91.

9. Triana JJ, Castañeda C, Parada L, Otálora-Esteban M, Rosselli D. Costo-efectividad de dabigatrán comparado con warfarina para el tratamiento de pacientes con fibrilación auricular no valvular. Rev Colom Cardiol. 2016;23:82-6.

10. Peña AG. Costo-efectividad de los nuevos anticoagulantes orales en pacientes con fibrilacion auricular no valvular en Colombia. Value in Health. 2015;18:A829-30.

11. Pearce A, Haas M, Viney R. Are the true impacts of adverse events considered in economic models of antineoplastic drugs? a systematic review. Applied health economics and health policy. 2013;11:619-37.

12. Harrington AR, Armstrong EP, Nolan PE, Malone DC. Costeffectiveness of apixaban, dabigatran, rivaroxaban, and warfarin for stroke prevention in atrial fibrillation. Stroke. 2013;44:1676-81.

13. Leigh P, White RH. An economic model of adverse events and costs for oral anticoagulants used for atrial fibrillation. Curr Med Reserch Op. 2007;23:2071-81.

14. Ministerio de salud y proteccion social. Sistema de información de precios de medicamentos. [Online] [Cited: 20 May 2015.] http://web.sispro.gov.co/WebPublico/SISMED/LibroVirtual/ index2.html.

15. Ruff CT, Giugliano RP, Braunwald E, Hoffman EB, Deenadayalu $N$, Ezekowitz MD, et al. Comparison of the efficacy and safety of new oral anticoagulants with warfarin in patients with atrial fibrillation: a meta-analysis of randomised trials. The Lancet. 2014;383:955-62.

16. Marseille E, Larson B, Kazi DS, Kahn JG, Rosen S. Thresholds for the cost-effectiveness of interventions: alternative approaches. Bulletin of the World Health Organization. 2015;93:118-24.

17. Guidelines for the economic evaluation of healthcare technologies in Colombia: technical support documents. Centre for Health Economics, University of York, York, United Kingdom. s.l. : Instituto de evaluación tecnológica en Salud, 2014.

18. Mogyorosy Z, Smith P. The main methodological issues in costing health care services: a literature review (No. 007cherp); . 2005.

19. Sheppard SR. Participatory decision support for sustainable forest management: a framework for planning with local communities at the landscape level in Canada. Canadian J Forest Research. 2005:1515-26, iv.

20. Green AO, Hunton-Clarke L. A typology of stakeholder participation for company environmental decision-making. Business Strategy and the Environment, 2003;12(5):292-9.

21. Fritsch O, Newig J. Under Which Conditions Does Public Participation Really Advance Sustainability Goals? Findings of a MetaAnalysis of Stakeholder Involvement in Environmental Decisionmaking. 2007 Amsterdam Conf Hum Dimens Glob Environ Chang. 2007;May:24-26. http://www.2007amsterdamconference.org/ Downloads/ AC2007_FritschNewig.pdf.

22. International Journal of Technology Assessment in Health Care, Health technology assessment. s.l. : 2009; 25.(S1).

23. Walker A. Challenges in Using MCDA for Reimbursement Decisions on New Medicines? Value in Health. 2016;19:123-4. 